ARCHIVO ESPAÑOL DE ARTE, LXXIX, 316

OCTUBRE-DICIEMBRE, pp. 403-425, 2006

ISSN: 0004-0428

\title{
VARIA
}

\section{TRES COBRES RESTITUIDOS A VÍCTOR WOLFVOET, EL MÁS FIEL SEGUIDOR DE RUBENS}

Tres cobres con atribuciones confusas en cuanto a su autoría o temática, pensamos de interés integrar en la producción de este pintor olvidado, Víctor Wolfuoet, que podría incluirse en la esfera de los pequeños maestros de pintura de género, con fecunda producción, y aunque falto de imaginación creadora, dotado de una técnica correcta y seductora gracia, que ha motivado confusiones con pintores de mayor rango ${ }^{1}$.

El desconocimiento, o la escasa divulgación de las pocas obras firmadas, salvo dos bocetos del Mauritshuis de la Haya, la Cabeza de Medusa (Dresde), y Cristo en casa de Simón (Museo del Louvre), ha dificultado siempre la identificación de las obras de Víctor Wolfvoet. Pero el hallazgo casual de una Alegoría a la Paz, atribuida erróneamente a Erasmus Quellimus, en el Museo de San Carlos de Méjico, fue un hecho afortunado para el estudio de los cobres que estudiamos aquí ${ }^{2}$. Esto nos proporcionó la posibilidad de conocer su estilo, la dicción de sus pinceles y colorido. Víctor Wolfvoet fue fiel a Rubens en sus composiciones, pero no logró asumir la fuerza dramática del maestro, ni su potencial expresivo. Además de la dependencia a Rubens, también la tiene a Van Dyck, con quien vinculamos el primer cobre de Venus y Marte (c. 66x51cm.) hoy en colección privada barcelonesa, objeto de este estudio, así como Los desastres de la guerra, en colección madrileña, y Los desposorios de la Virgen, de la Seo de Zaragoza.

\footnotetext{
${ }^{1}$ M.L. HaIrs, Dans le Sillage de Rubens les Peintres d'Histoire anversois au XVII e siècle, 1968, pp. 221- 222.

2 M. Díaz Padrón, "Dos cobres de Víctor Wolfvoet en el Museo de San Carlos de Méjico", Boletín del Seminario de Estudios de Arte y Arqueología, LXV, 1999, p. 323
} 


\section{Venus y Marte}

Venus y Marte (fig. 1) están diseñados en aspa. Ella sentada y arrodillado el dios, junto a un árbol con las ramas y hojas que sirven de dosel. Acompañan a los dioses dos amorcillos, uno sostiene las riendas del caballo y otro el casco en lo alto: dos atributos del dios, a los que se une un bastón de mando, típica insignia de los generales españoles del siglo XVII. Marte cubre su coraza con una espesa capa azul oscuro, y Venus su cuerpo con una túnica blanca y manto rojo. La diosa rodea a Marte con el mágico cíngulo, con que domina la voluntad de los dioses y los hombres que sucumben a sus encantos. La historia de estos amores la narra la Ilíada (V, 825), la Odisea (VII, 266-366) y Ovidio en la Metamorfosis (IV, 171-189), y recordada en la iconografía antigua de todos los tiempos, donde el Amor es la causa de desdichas y alegrías 3 .

Hemos localizado la fuente de la composición de Víctor Wolfvoet, en un lienzo de Van Dyck, grabado por Conraed Waumans 4 (figs. 2 y 3). Dos pinturas conocemos de esta composición de Van Dyck, una en la galería Colonna ${ }^{5}$, y otra en la antigua colección del Príncipe de Condé6. La primera se tiene por obra del taller de Van Dyck en la última monografía del pintor; y la segunda, (que se pregunta en la citada monografía si es la misma u otra) es sin duda otra. Hay pequeñas diferencias entre las dos, la de Colonna tiene ramas a los pies de Venus y hojas; mientras en la del Príncipe de Condé el suelo es liso, además de una notable rotura a la altura del brazo que Marte apoya en su bastón de mando. Es posible que esta última pintura, sin localizar, sea el original que sirve al grabado. El estado de conservación dificulta un juicio satisfactorio. El rostro de Venus embelesada y la mirada del dios conecta bien con la idea que los pintores tienen de esta historia a través de los textos clásicos7. El canon más estilizado de esta pintura de Van Dyck, es propio de su estilo. Van Dyck proyecta en un boceto existente en la galería de pintura de la iglesia de Oxford (1630-1632) el instante inmediato a la despedida de los amantes, puestos en pie y antes de Marte partir para la guerra ${ }^{8}$.

El tema que aquí se revive está tomado de la más remota Antigüedad en los frescos de Pompeya (s. I.d.C.), en la casa de Venus y Marte del Museo de Nápoles, y en el Renacimiento. La composición de Van Dyck y su trasvase al cobre de Víctor Wolfvoert que estudiamos deriva del Amor de los dioses de Veronés (Metropolitan de Nueva York). Es oportuno insistir en la iconografía de la escena que hemos adelantado, pues en el catálogo de la galería Dorotheum de Viena, se tenía por los amores de Raimundo y Arminda, del Canto XIV (10-18) de la Jerusalén Libertada de Torcuato Tasso9 ${ }^{\text {. Recti- }}$ ficamos esta interpretación por la presencia del caballo y el cíngulo de Venus rodeando a Marte, entre otros pormenores iconológicos, que dan indicios para dudar que se tratara de aquella epopeya historiada, inclinándonos por el episodio de la mitología clásica.

Reforzó nuestra tesis, la localización del grabado de Conraed Waumans, basado en la pintura de Van Dyck. El grabado invertido es idéntico al cobre, como puede verse cotejándolo; salvo

\footnotetext{
3 E. WIND, Pagan Mysteries in the Renaissance, 1958, p. 84

${ }^{4}$ F.W.H. HollsteIn, Dutch and Flemish Etchings, Engravings and Woodcuts ca. 1450-1700, vol. 51, p.115, n ${ }^{\circ}$ II

5 E.A. SAfariK, Catalogo sommario della Galleria Colonna in Roma. Dipinti, Busto Arsizio 1981, nº 67, ( Catalogada con reservas, por Horst Vey, en la última monografía de Van Dyck, S.J. BARnEs, et al, Van Dyck. A Complete Catalogue of the Paintings, 2004, p. 404, III.A12. Esta copia se restituye hoy a Bosschaert por A. HEINRICH, Thomas Willeboirts Bosschaert (1613/14-1654)Ein flämischer nachfolger Van Dycks, Turnhout, 2003, T. I, p. $311, \mathrm{n}^{\circ} 148$

6 Lienzo, 58 x 46 pulgadas. Procede de la colección del Principe de Condé en el siglo XVIII, Frankfurt; Christie's 8-5 1813, n 75; Col. Sir. Richard Clayton de Adkington: el conde de Crawford y Balcanes; Christie's 11-10-1946, nº 166, adquirido por F. Sabin.

7 Aguion-Barbillon-Lissarrague, Héroes y dioses de la Antigüedad, Madrid, 1997, p. 526.

8 Byam Shaw, Paintings by Old Masters at Christ Church, Oxford. London, 1967, n 248; E. LARSEN The Paintings of Van Dyck, II, p. 294, n 739 .

${ }^{9}$ Dorotheum, 2 octumbre 2002, no 160
} 
Figura 1. V.Wolfvoet, Venus y Marte. Colección privada, Barcelona.

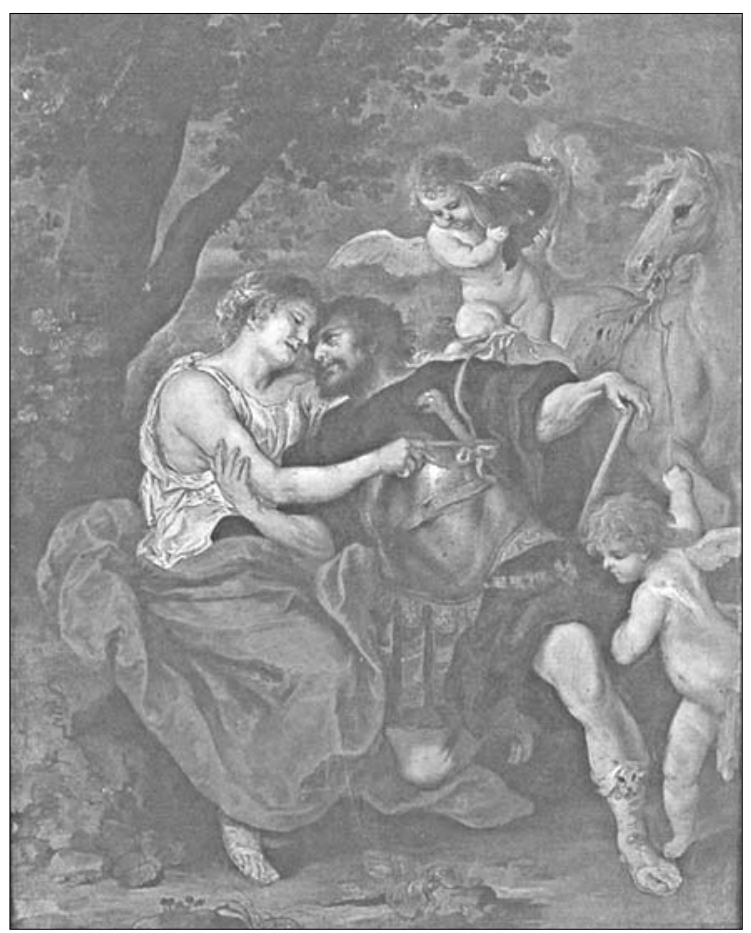

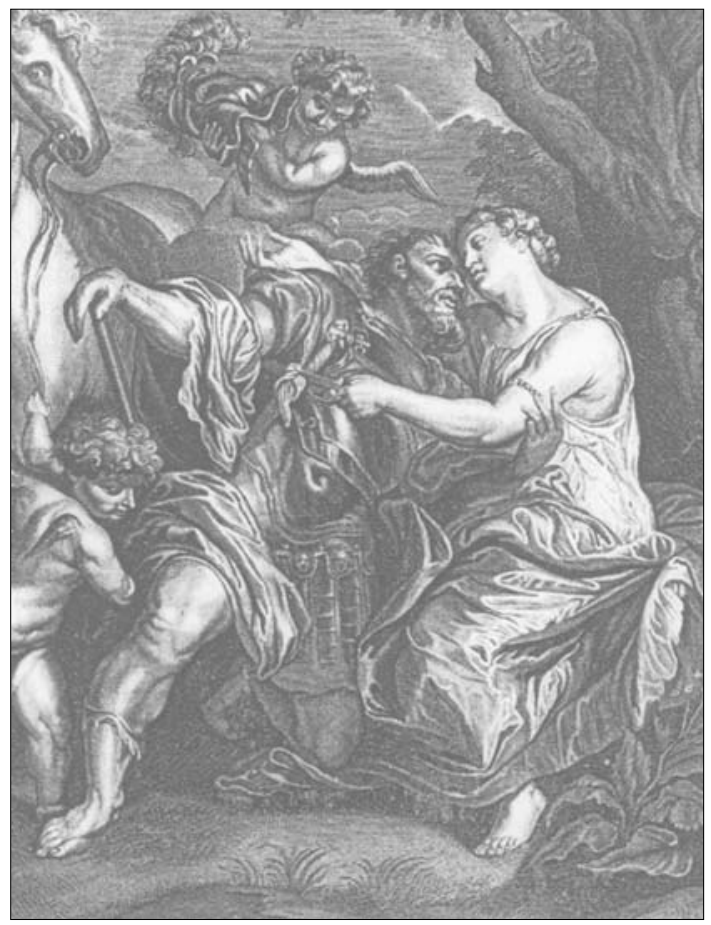

Figura 2. C. Waumans, grabado según Van Dyck Venus y Marte.

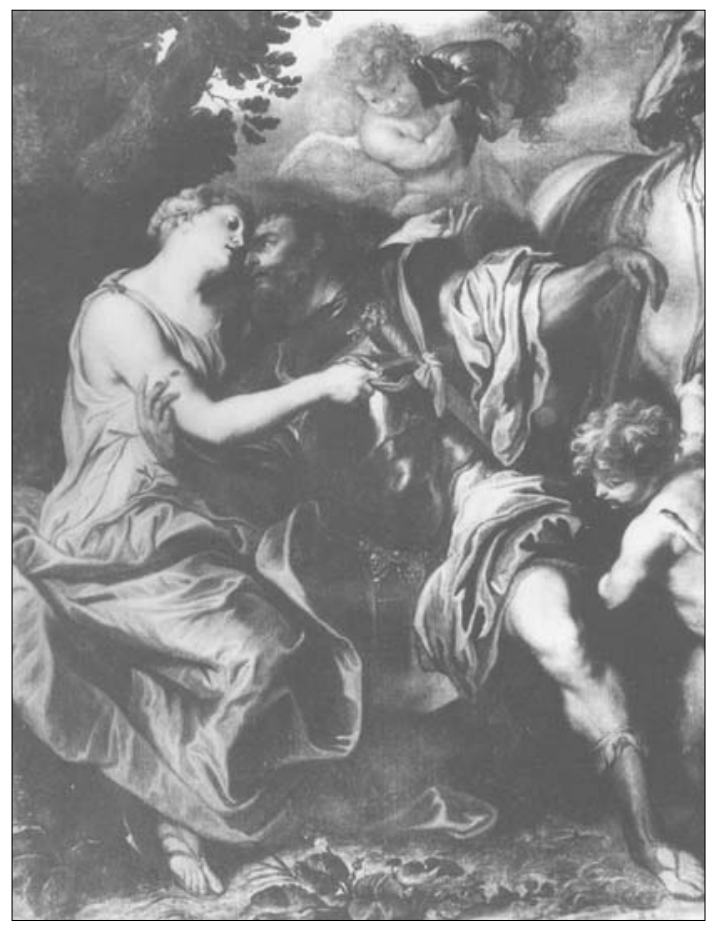

Figura 3. Van Dyck, copia por W. Bosschaert, Venus y Marte. Galería Colonna, Roma.

AEA, LXXIX, 316, OCTUBRE-DICIEMBRE, 403-425, 2006, ISSN: 0004-0428 
un mayor espacio en el fondo y dispersión del ramaje del árbol, sin olvidar sutiles variantes de los modelos, que ajusta Víctor Wolfvoert a los suyos.

La leyenda del grabado lleva dos rótulos que ratifican el contenido propuesto y confundido en la galería vienesa: Marte dejándose llevar por Venus según Antón Van Dyck. "Norunt, etiam Potemtem, Cupidines exarmare, (debajo a la izquierda) Antonius van Dyck pinxit, (centro) Coenrardus Waumans sculpsit, (a la derecha), Ioannes Meijßens excudit Antuerpiae." En una segunda estampación el texto es: "Norunt Potentem, Cupidines Exarmare", seguido de tres líneas en latín con la dedicatoria: "Excellentissimo Domino D. Maximiliano Wilibaldo: Truxhio. S.R. Imperio haereditario, Comiti de Wolfegg Baroni de Waltbourg, ... observand L.M.D.C.Q. Ioannes Meyßens", con el escudo de armas en el centro: Coburg, Dresden, Rótterdam, Viena ${ }^{10}$.

Los rasgos del rostro de la joven y angelitos del grabado, junto al dios, nos permite reconocer modelos de Van Dyck, aunque bajo la estela inevitable de Rubens en la composición. Las actitudes y modelo del caballo recuerdan los de Dido y Eneas de la Stäldeltsches Kunstinstitut de Frankfurt y boceto de la galería Agnew de Londres ${ }^{11}$. Más expresivo para reconocer esta influencia es el dibujo atribuido a Rubens, con igual asunto y composición en el Cleveland Museum ${ }^{12}$ (fig. 4). Esto facilita fijar una fecha límite para el cobre que nos ocupa.

El cobre es una copia, como fue frecuente en este discípulo de Rubens y consta en las referencias de su vida. De aquí el reconocimiento del estilo de Rubens en la obra de Van Dyck que le sirve de fuente directa. Víctor Wolfvoert se somete literalmente al grabado, con escasos destellos de su propio lenguaje. Es la tendencia a sombrear la nariz en la parte inferior y sus pequeñas figuras, la falta de vigor y la suave tonalidad cromática lo que le separa de sus fuentes. Invierte el universo vigoroso de Rubens en el suyo: gracioso y menudo, reduciendo la grandeza de la historia a imágenes con más intención de deleitar que emocionar.

Este cobre de Venus y Marte de la colección barcelonesa nos ha permitido identificar varias réplicas con escasos cambios en accesorios y paisajes. Todas con atribuciones equivocas o en el anonimato, y confundiendo la historia de Arminda y Reinaldo, como en este caso, o Dido y Eneas. La mayor parte han aparecido en el comercio de Londres: en Sotheby's como anónimo de escuela flamenca (28-II-1990), y cuatro años después en la misma galería en Nueva York (19-V-1991, no 205); otro en la antigua colección Finck de Bruselas en 196413; otro como escuela de Van Dyck, y como Dido y Eneas en la colección J. Vries en Arhem (1937); otro como seguidor de Rubens en Hannover, aunque más tosco en su factura ${ }^{14}$; y puerta izquierda del bargueño de la Rubenshuis en Amberes ${ }^{15}$. No es extraña la producción reiterada de este

\footnotetext{
${ }^{10}$ Ch. Blanc, Historire des peintres. École flamande, París, 1868, p. 44; A.V. WuRzBACH, Niederländisches Künstler-Lexikon auf Grund archivalister Forschungen bearbeitet, Viena-Leipzig, 1901-1911, p. 42; F.W.H.HoLlSTEIN, Dutch and Flemish Etchings, Engravings and Woodcuts (1450-1700), VI, Amsterdam, 1949-1969, p. 832; C. DEPAUw, G. LUIJTEN Antoon van Dyck en de prentkunst, Amberes, 1999, p. 380.

11 E. Hubala, P.P.Rubens. Die Gemälde im Städel, Städelsches Kunstinstitut und Städtische Galerie, Frankfurt, 1990 , p. $45, \mathrm{n}^{\circ} 120$. Procede del Alcázar y una copia hizo Mazo que se encuentra en el Museo del Prado. M. Díaz PADRÓn, El siglo de Rubens en el Museo del Prado, Madrid, 1995, tomo II, p. 1152.

12 La atribución a Rubens se tiene con reservas por E. Mc. GRATH Subjets from history, Corpus Rubenianum L.. BuRCHARD, Londres, 1997, VI, p, 153, nº 43 b.

13 'S Gravenhage, Waart and Zonen, venta 23-24 de abril, 1963, n' 37; Cat. Exp. Maitres Flamands, 23-XI al 8-XII, 1963, nº 25; Bruselas, Galería Alexander Finck (Cat. $3^{\mathrm{a}}$ exposición, 28-II al 13-XII de 1964, nº 29). Existe un pandant de esta obra que perteneció a Finck y en exposición de 1963 con el número 24, ambos atribuidos a Hendrick y Jan van Balen.

14 Die holländischen und flämischen Gemälde des 17 Jahrhunderts, Hannover, 2000, p. 309. Tradicionalmente en el siglo XIX se pensaba en el encuentro entre Enrique II y Diana de Poitiers, como una alegoría política (G. Kestner, $\left.1849-1867, \mathrm{n}^{\circ} 77\right)$

15 HuvenNe-Nieuwdorp, La maison de Rubens , 1990, p. 102, nº inv. M. 166.
} 
seguidor de Rubens, pues consta en su testamentaría ${ }^{16}$, que Víctor Wolfvoet poseía en su taller 35 copias, 20 bocetos y ocho pinturas de Rubens. Los antiguos tratadistas no olvidan esta estrecha dependencia con el maestro. Tampoco extraña la utilización de los grabados que fue materia del comercio de su padre.

Es oportuno detenernos en la Visitación de Saint-Jacques de Amberes, tenida tradicionalmente por obra de Víctor Wolfvoet ${ }^{17}$, sin que encontremos vínculos estilísticos entre esta pintura y las conocidas seguras del pintor. La primera noticia la da a mediados del siglo XVIII, el pintor holandés Jacques de Wit que visitó la iglesia (donde hoy podemos verla). Théodoro Van Lerius ${ }^{18}$ la atribuye a Víctor Wolfvoert, y data aproximadamente en 1639, seguramente en relación a datos de la capilla. Posteriormente Wurzbach hace mención de una firma, "V.Wolfvoet 1639"19, que la profesora Hairs no localiza en revisión última del lienzo ${ }^{20}$, lo que refuerza nuestra tesis. El estilo de esta Visitación, está más próxima a Simon de Vos, a cuyos pinceles es posible restituir. Es un pintor importante y próximo a Van Dyck. Gusta de los ritmos curvilíneos y sombras envolventes que lo distancia del pintor que tratamos. Posiblemente, la autoría equívoca, a nuestro modo de ver, de la Visitación de Saint-Jacques, ha sido un obstáculo para el estudio de Víctor Wolfvoet.

\section{Los males de la guerra}

Es fácil reconocer en este segundo cobre (c. 51x62), que añadimos al catálogo de Víctor Wolfvoet (fig. 5), Los males de la guerra que Rubens pintó para el Gran Duque de Toscana, y hoy conserva la pinacoteca del palacio Pitti de Florecia ${ }^{21}$ (fig. 6). Es una repetición trabajada con pulcritud, del original de los últimos años de Rubens, de técnica valiente y fogosa. La ardiente gama cromática conjuga con el efectista impulso diagonal y la carga de trágicos augurios que arrastra tras sí. La intencionalidad de esta obra está en la carta de mano del mismo Rubens a su amigo Justo Suttermans (12-03-1628), tan apasionante como las imágenes de la pintura. Es interesante transcribirla, por reflejar las ideas del original del maestro, y la exquisita reducción del discípulo.

Es evidente la intención de Víctor Wolfvoet de propagar los ideales más nobles de su maestro, como fue la lucha por la paz: " La figura principal es Marte saliendo del templo de Juno, cerrado en tiempos de guerra, siguiendo la costumbre romana, con el escudo en el brazo y la espada sangrante en la mano, amenazando a los pueblos con las mayores calamidades. No le preocupa Venus, su amada, que le besa y se esfuerza en detenerlo con cariño, acompañada por Cupido y Amorcillos. De otra parte, Marte es arrastrado por la furia Alecto con su antorcha en la mano. A su lado vemos monstruos, la peste y el hambre, inseparables compañeros de la guerra. En tierra

\footnotetext{
16 J. DenucÉ, Inventare von Kuntssammlungen zu Antwerpen im 16 und 17 Jahrhundert, La Haya, 1932, p. 138-155; Ídem, Na Peter Pauwel Rubens. Documenten uit den kunsthandel te Antwerpen in de 17 e eeuw van Matthijs Musson, Amberes, 1949, pp. 104-129.

17 M.L. HAIRS, op.cit, 1968, p. 221, n. 30; J. De Wit, De Kerken van Antwerpen. Ed. Boschere, 1910 (1748), p. 36; M. Díaz PAdrón, "Simon de Vos y la Visitación de Saint-Jacques de Amberes atribuido a Víctor Wolfvoet" Archivo Español de Arte, (en prensa).

18 T.VAn Lerius, Notice des ouvres d'art de l'églese St Jacques, Amberes, 1855, p. 129 ; M.L. HAIR, op. cit., 1968, p. 221, n. 30

19 A.V.WuRZBACH, Niederländisches Künstler-Lexikon auf Grund archivalischer Forschungen bearbeitet, Viena, 1906-1911, II, p. 898

20 M.L.HAIRS, op.cit., 1968, p. 221

21 N.Cipriani, La galleria Palatina nel Palazzo Pitti a Fiorenze, Repertorio ilustrato de toti i dipinti,,le scultere,gli a ffeschi e gli arredi...1966, p. 72
} 


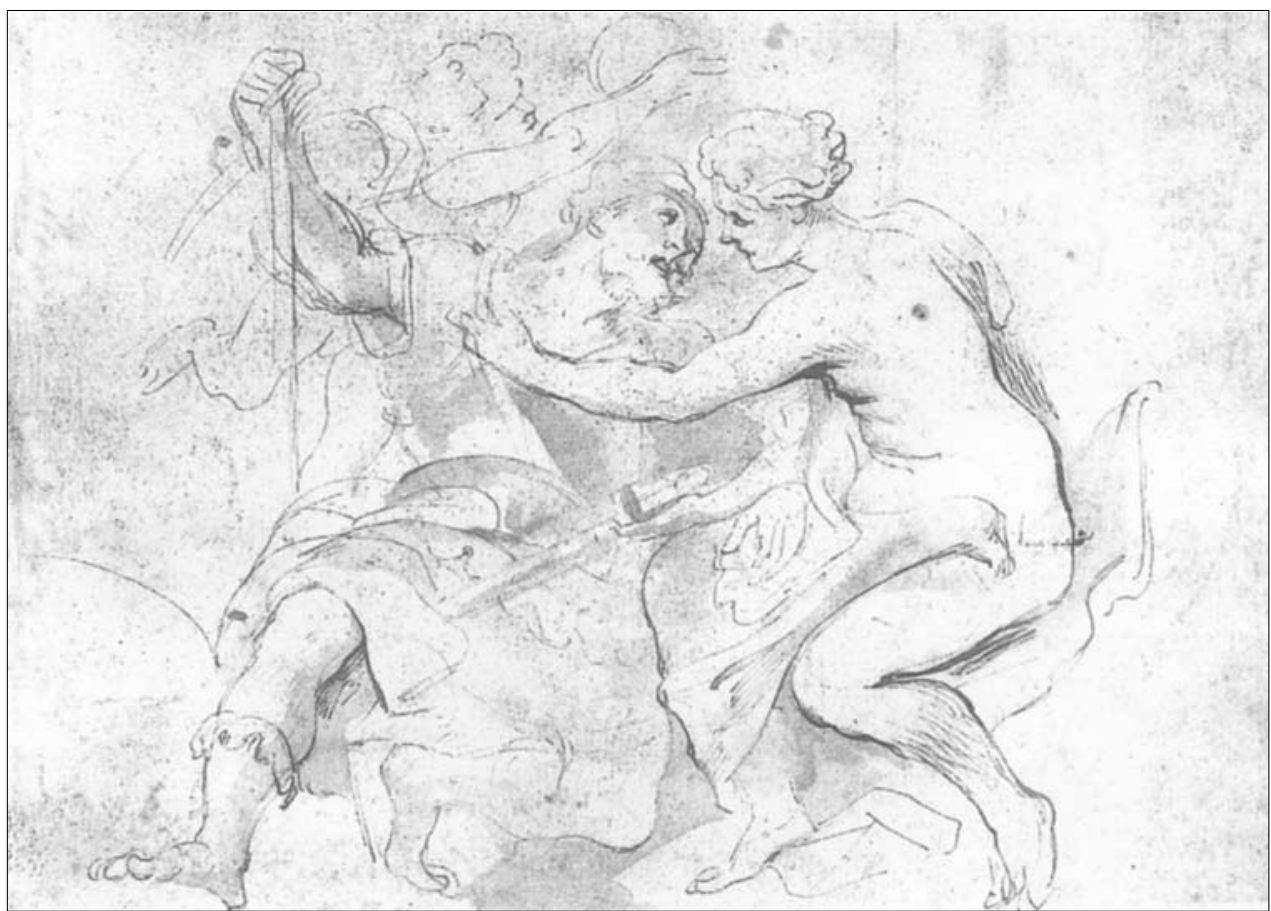

Figura 4. Rubens(?) Venus y Marte. Cleveland Museum.

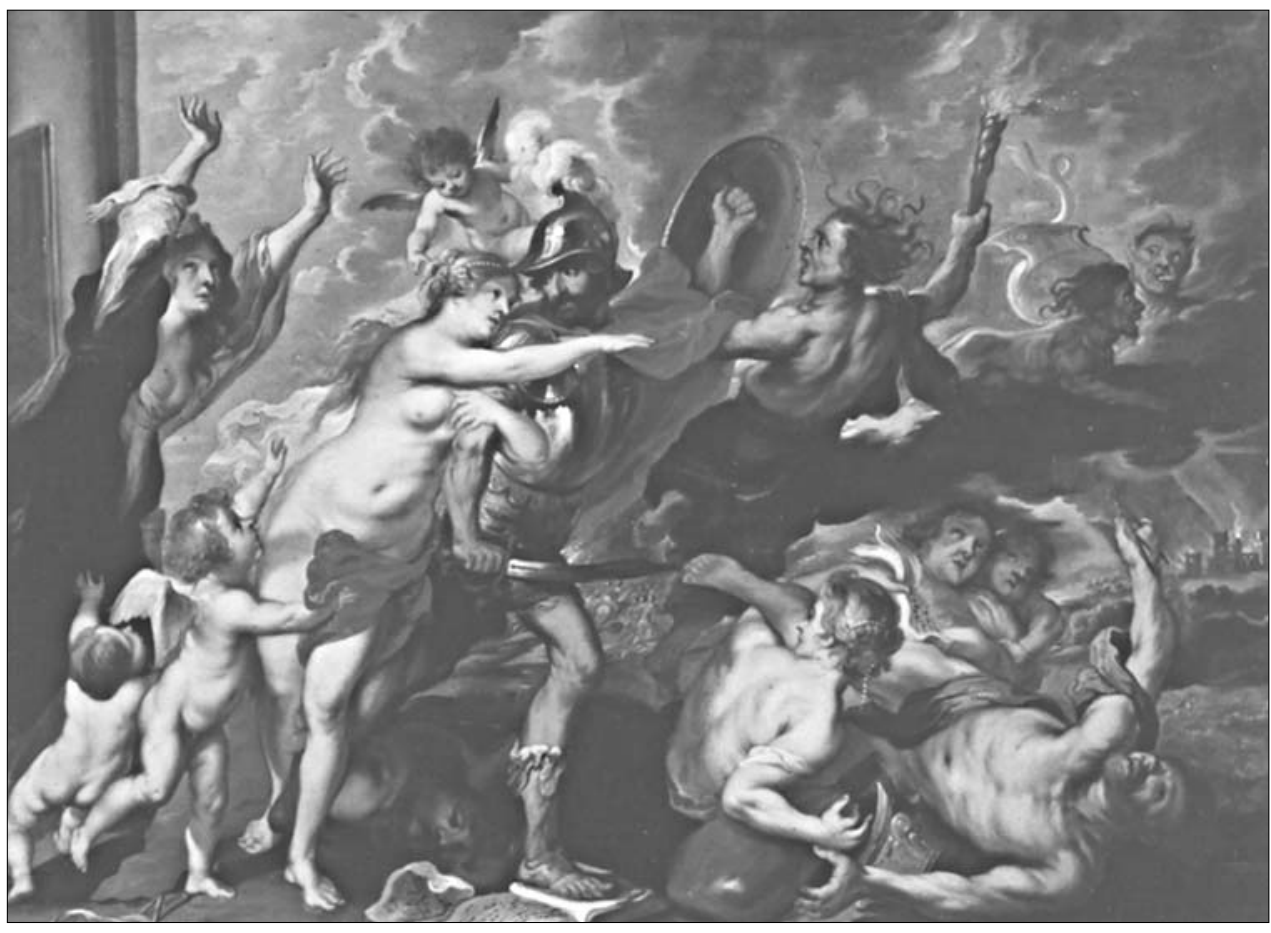

Figura 5. V. Wolfvoet, Los males de la Guerra. Colección privada, Madrid.

AEA, LXXIX, 316, OCTUBRE-DICIEMBRE, 403-425, 2006, ISSN: 0004-0428 
yace una mujer con un laúd roto, símbolo de la armonía, incompatible con la discordia y la guerra; otra mujer con su hijo en brazos, personifica la fecundidad, la maternidad y la caridad, afectadas por la guerra que destruye todo. También vemos un arquitecto caído, con sus útiles en mano, que quiere decir que todo lo construido en tiempo de paz, para utilidad y ornamento de las ciudades, se destruye y arruina por la violencia de las armas. Si no recuerdo mal, -continúa la carta de Rubens- verá también en el suelo, bajo los pies de Marte, un libro y unos dibujos. Significa que el dios aplasta bajo sus pies las letras y todo lo que es bello. También hay un carcaj con flechas y jabalinas, que unidas simbolizan la concordia, y el caduceo de Mercurio, y las ramas de olivo símbolos de la paz, yacen en el suelo, donde han sido arrojados. La mujer de luto, vestida de negro sin joyas ni abalorios, y cubierta por un velo rasgado, es la desdichada Europa, desolada tanto tiempo por los saqueos devastadores y las miserias, que juntos causan daños irrecuperables. Su atributo es el globo terrestre, que lleva un ángel o un genio, coronado por una cruz como símbolo del mundo cristiano"22.

La pintura de Rubens y la copia de Víctor Wolfvoet, incita a concienciar a los hombres de "los males que la guerra engendra" en frase de Mac Rooses ${ }^{23}$. Tal como Rubens escribe, el centro lo ocupa Marte, el dios de la guerra, que avanza con su espada ensangrentada, y las furias asolando los campos y ciudades, matando a las familias y destruyendo las artes y las letras. A la izquierda está el templo de Juno, ahora con las puertas abiertas como aviso del comienzo de la guerra. La mujer con los brazos abiertos, encarna la Europa sufriente, con el genio llevando la bola del mundo con la cruz de la cristiandad. A la derecha, aún más aterrador está el grupo de la Discordia, la Furia, la Peste y el Hambre, con un fondo de cielo amenazante. El hombre con compás, junto a un capitel, simboliza la destrucción de los monumentos por la guerra. También ilustra la angustia de la Maternidad, la Familia y la Caridad arrasada, como el libro, los dibujos, el caduceo y el olivo, símbolos estos de la cultura y la paz.

Víctor Wolfvoet copió con fidelidad la composición y los modelos del original. Contrasta la carne desnuda de Venus con el frío metal de la armadura de Marte, quien vuelve el rostro hacia la diosa. Es un bello juego rítmico de expresión y diseño.

Pensamos que Víctor Wolfvoet copió directamente el original o bocetos de Rubens, pues por su testamentaria ${ }^{24}$ sabemos que poseyó algunos. Esto parece justificarse por la fidelidad de los colores, que no trasciende en los dibujos y grabados. Es oportuno recordar, que los grabados de esta composición son posteriores a las pinturas ${ }^{25}$. La dependencia a la composición de Rubens es total, salvo algunos pormenores que omite, tales como la robusta columna del templo y el geniecillo que mira al espectador, con el globo terráqueo, a la izquierda. Tampoco logra la calidad, intensidad cromática y la fisonomía de Helena Fourment que Rubens dibujó en el rostro de Venus. El discípulo la sustituye por su personal prototipo. El diseño de la nariz con sombra en las fosas nasales, que repite igual en las alegorías de Europa y las Furias, nos sirve para un primer encuentro con su morfología estilística. También renuncia a las carnaciones cálidas y nacaradas del original. En Wolfvoet dominan los tonos rosas con sombras oscuras, sin el correcto enfoque de la luz. También cubre el cielo de un gris uniforme, cuando Rubens lo matiza con azules claros y ocres tormentosos, diferenciando dos zonas.

La copia en cobre, nos sirve de testigo para completar la parte izquierda del original del Palacio Pitti, que posiblemente fue mutilado en el borde del lado derecho, por adaptar un bastidor, pues secciona parte de la cabeza de una de las furias y el arquitecto.

22 M.Rooses-CH.RuElens, Correspondance de Rubens et documents épistolaires concernants sa vie et ses oeuvres, VI, 1909, pp. 206-208

23 M. Rooses, l'Ouvre de P.P.Rubens, 1886-1892, IV, p. 47

24 M.L. HAIRS, op. cit., 1968, p.221

25 D.BodART, Rubens e l'incisione, Roma, 1977, p. 185, nº 410 
Los males de la guerra de Rubens tuvo pareja ideológica en la Alegoría de la Paz, que pintó para Carlos I de Inglaterra. Pero esta paz soñada, se truncó en la visión de Florencia y la copia de Wolfvoet. La paz es un ideal que el pintor intentó forjar, con ocasión de la misión diplomática que protagonizó en Madrid y Londres ${ }^{26}$. Fue una misión en la que Rubens puso la misma pasión que en sus pinceles.

La imagen doliente de Europa con los brazos abiertos de Los males de la guerra, sirvió para propagar la misma denuncia por las miserias que asolaron a Europa. Nadie imaginaría que en tiempos venideros (cuatro siglos después) esta composición sería la fuente para un maestro español del siglo XX: Picasso ${ }^{27}$, tan cubista y abstracto, utilizó en el Guernica estas imágenes profundas del barroco de Rubens para su protesta por los horrores de la guerra que le tocó vivir.

\section{Los desposorios de la Virgen}

También de Víctor Wolfvoet es el cobre con Los Desposorios de la Virgen de la Sacristía Mayor de la Seo de Zaragoza (c. 87x69,5 cm) (fig. 7), publicado recientemente por Carmen Morte, entre los anónimos de la Escuela de Rubens, que estudia con ocasión a la exposición iconográfica de la Virgen en tierra aragonesa ${ }^{28}$. Víctor Wolfvoert copia otro original de Rubens, pero desaparecido en este caso, de la Iglesia de Santa Isabel de Sión en Bruselas. Rooses en el siglo XIX recoge las referencias más completas de esta pintura, las copias y los grabados $\operatorname{conocidos}^{29}$.

Importante es el grabado de Schelte à Bolswert (fig. 8 ), pues reproduce el original del maestro. Podía pensarse en la utilización del mismo grabado por Víctor Wolfvoet ${ }^{30}$, pero existen diferencias en pequeños detalles examinados que dan pie para pensar en la utilización directa del original. Destacamos la presencia del Espíritu Santo en el cobre de la Seo y la mayor amplitud en el pavimento del templo, dominando los colores cálidos sobre los fríos y el blanco de la túnica de la Virgen con vibrantes reflejos del satén.

A la escueta cita de San Mateo del anuncio de los desposorios: "Su Madre, María, estaba desposada con José y, antes de vivir juntos, resultó que había concebido por la acción del Espíritu Santo" (Mateo, I, 18.), habría que añadir los ensueños de los Evangelios Apócrifos que transmiten la secuencia de este momento representado con deuda a la imaginación de Italia. En el eje de la composición están San José, la Virgen y el Sumo Sacerdote, que le entrega un anillo de piedra verde, no de oro, plata o cualquier otro metal. Es un detalle que el pintor acierta en la composición. Ha sido omitida la aglomeración y las gesticulaciones habituales en las representaciones medievales, para ofrecernos aquel encuentro en el vestíbulo del Templo. El decorado corresponde al usual en Occidente, donde el acto según los judíos, no era un sacramento ${ }^{31}$. Entre las mujeres está Santa Ana a las espaldas de la Virgen, que a veces figura entre los invitados.

Es razonable pensar que el origen de este cobre y los restantes de la Catedral de Zaragoza, está en su importación del norte de Europa en el siglo XVII. Es sabido que el comerciante de obras de arte Mathiens Musson, exportó cobres de Amberes a los Puertos de Sevilla, Cádiz y Nueva Espa-

26 F. Boudouin, P.P.Rubens, Amberes, 1977, p. 253

27 S. Sebastián LóPEZ, "La clave del Guernica", Boletin Museo e Instituto Camon Azmar, no 5, 1981, p.5. El Guernica y otras obras de Picasso. Contextos iconográficos. Murcia, 1984, pp. $94-104$

28 Exp. Cat. María, fiel al Espíritu. Su iconografía en Aragón de la Edad Media al Barroco, del 8 de septiembre al 10 de noviembre de 1998. Museo Camón Aznar, Zaragoza , p. 98, nº 7.

${ }^{29}$ M. Rooses, op.cit., 1886-1892, V, p. 148, no 142

30 D. BodART, op.cit., 1972-1977, nº 39; F.W.H. Hollstein, op.cit, 1949-1969, III, p. 71, nº 3

${ }^{31}$ L. Reau, Iconogafía, II, París, 1957, p. 171.

32 M. Díaz Padrón, op. cit , Boletín del Seminario de Estudios de Arte y Arqueología, LXV, 1999, p. 323. 


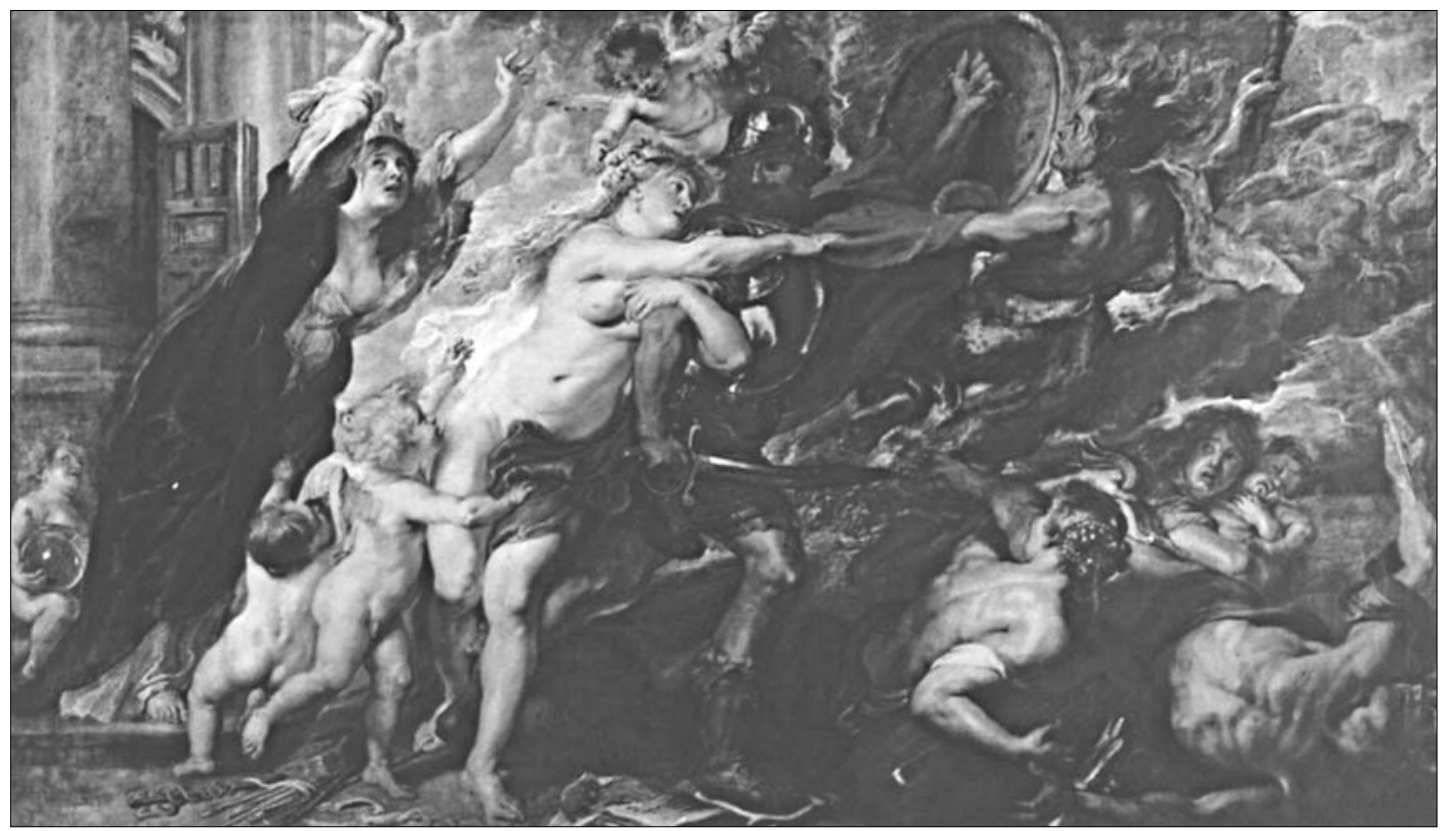

Figura 6. Rubens, Los males de la Guerra. Palacio Pitti, Florencia.

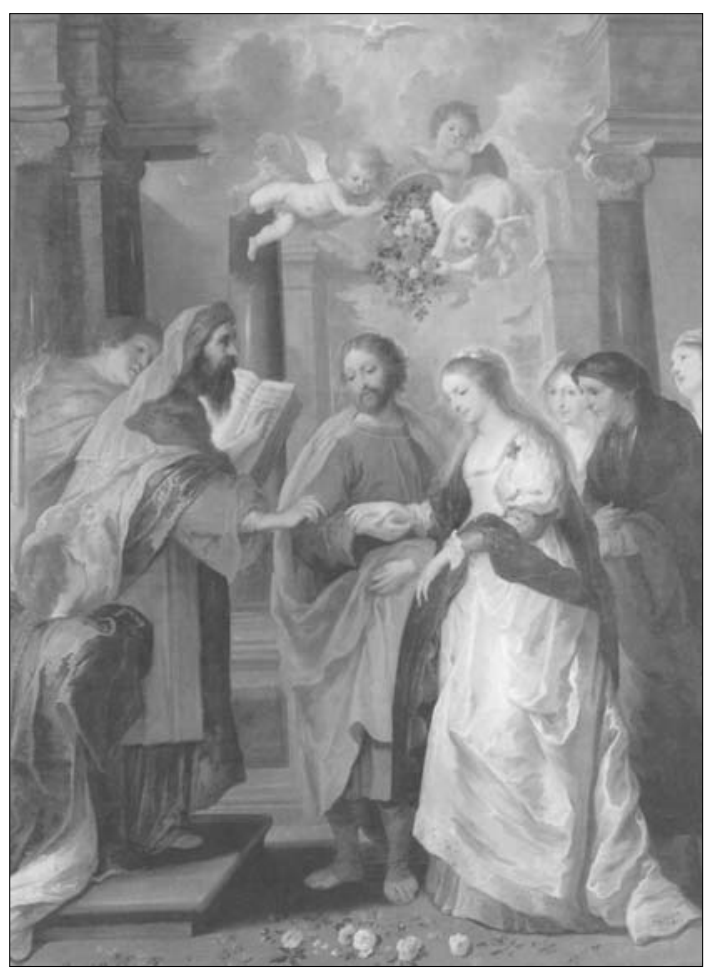

Figura 7. V. Wolfvoet, Los desposorios de la Virgen. Seo, Zaragoza.

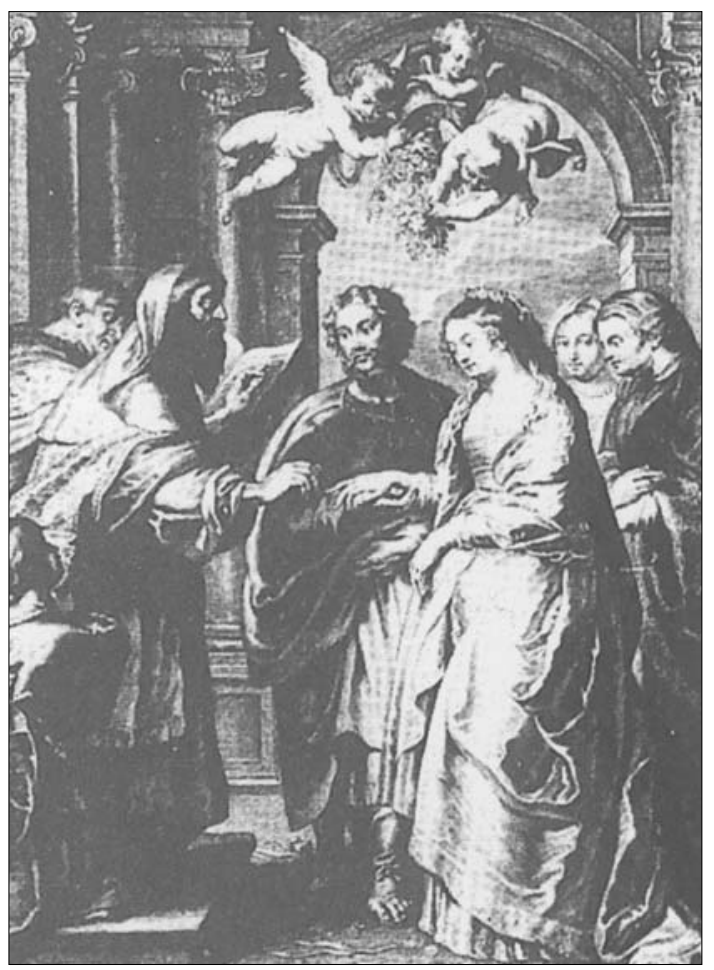

Figura 8. Schelte à Bolswert, grabado según Rubens. Los desposorios de la Virgen.

AEA, LXXIX, 316, OCTUBRE-DICIEMBRE, 403-425, 2006, ISSN: 0004-0428 
$\tilde{n}^{32}$. También existe otra vía a través de la franja cantábrica, desde donde llegan al interior de Castilla y Aragón. El hecho es que Víctor Wolfvoet tuvo igual fortuna en la Península Ibérica que Frans Franken II, W. Van Herp, P. Van Lint o A. Willenssen, de quienes hemos tenido ocasión de tratar estos últimos años.

Pero, el interés de esta excelente copia, está fundamentalmente en la identificación de su autor, como las dos otras reunidas en la exposición del Museo Camón Aznar. Hemos analizado el estilo de Víctor Wolfvoet tratando los dos cobres que preceden, con escenas mitológicas, alegóricas y dramática violencia. Éste, sin embargo, nos brinda un remanso equilibrado y reflexivo, en la forma y el sentimiento. A no ser por el conocimiento del estilo del pintor y la naturaleza del soporte, podría pasar por un copista de Rubens del siglo XVIII. El fino y correcto rostro de San José nos podría llevar a un razonable equívoco.

Esta última composición aproxima a comprender mejor la personalidad de Víctor Wolfvoet. Es una composición triangular y más acorde con su sensibilidad. Insistimos en su voluntad artística, tan distante de la vitalidad de Rubens en la concepción formal, cromática y expresiva. A pesar del servilismo al diseño, la sombra en los ojos, bajo la nariz y dulce factura, delata una personalidad opuesta al alma del maestro. Es uno de tantos pintores de indudable calidad de la escuela de Amberes, atrapado en la órbita del maestro.

MATías DíAz PADRóN 